\title{
A Theoretical Consideration on Heat Transfer in Fire Resistance Furnaces for Furnace Harmonization
}

\author{
KAZUNORI HARADA \\ Building Research Institute \\ Ministry of Construction \\ Tatehara 1, Tsukuba 305 Japan \\ YUKIHIRO YABUKI \\ Hazama Corporation \\ Nishi-Shinjuku 4-4-12, Shinjuku, Tokyo 160 Japan \\ TOSHIO TERAI \\ Kinki University \\ Takaya-Umenobe 1, Higashi-Hiroshima 729-17, Japan
}

\begin{abstract}
To discuss the possibility of furnace harmonization, heat transfer in fire resistance furnaces were analyzed numerically. The analytical model included radiative and convective heat transfer between surfaces and gas volume. The heat exchange between thermocouple and its surroundings was taken into account in order to simulate the furnace control process. The model was verified by comparison with experimental data. By using the model, calculations were carried out for various furnace depth, fuel, wall lining materials and the geometry of thermocouples for furnace control. From the calculated results, it was concluded that the wall lining material is the main factor that controls the heat impact on specimen. The geometry of thermocouple is a secondary factor.
\end{abstract}

Key words: fire resistance test, furnace harmonization, wall lining materials, furnace depth, fuel, thermocouple geometry

\section{INTRODUCTION}

It is recognized that the fire resistance test results scatter by various factors. One of the reason is the difference in the heat impact on specimen. Existing furnaces differ in constructions such as furnace size, fuels, wall lining materials and so on. Thus the scatter of the results is inevitable. A key for harmonization is to standardize the wall lining materials. The other way could be to use the plate thermocouples that is less sensitive to gas temperature, but sensitive to radiative environment. Original ideas were proposed by Wickström ${ }^{1)}$. A series of tests were carried out by Cooke et al. They found that the scatter of the results were reduced to a certain degree when they applied the plate thermocouples for 
furnace control ${ }^{2)}$.

As mentioned above, there are two proposals to harmonize the fire resistance furnaces. What is lacking is the information on the importance of these proposals. In this study, a model of heat transfer was developed to investigate how the heat impact on specimen is changed by furnace constructions. Using the model, a series of calculations were carried out to investigate the importance of furnace size, fuel, wall lining materials and the geometry of thermocouples for furnace control. Based on the calculated results, the way to achieve furnace harmonization is discussed. Similar analytical approaches were taken by Wakamatsu $^{3)}$ and Harmathy ${ }^{4)}$. However, in order to discuss the effect of geometry of thermocouple for furnace control, the present model includes the heat balance of thermocouples.

\section{A MODEL OF HEAT TRANSFER IN FIRE RESISTANCE FURNACES}

A physical model of heat transfer in fire resistance furnaces was developed to investigate the importance of wall lining materials, gas composition and the geometry of thermocouple for furnace control. Schematic idea of the model is shown in Figure 1. The furnace shape was approximated by a rectangular parallelepiped. Radiative and convective heat exchange between specimen/wall surfaces and gas volume were taken into account together with heat conduction in specimen and furnace walls.

In fire resistance tests, the furnace is controlled to fit the thermocouple temperature to standard time- temperature curve. To simulate this process, radiative and convective heat exchange between the thermocouple and its surroundings was taken into account to calculate the thermocouple temperature. Then, the gas temperature is corrected to fit the thermocouple temperature to standard time temperature curve. A preliminary version of this model was already presented ${ }^{5)}$ by the authors.

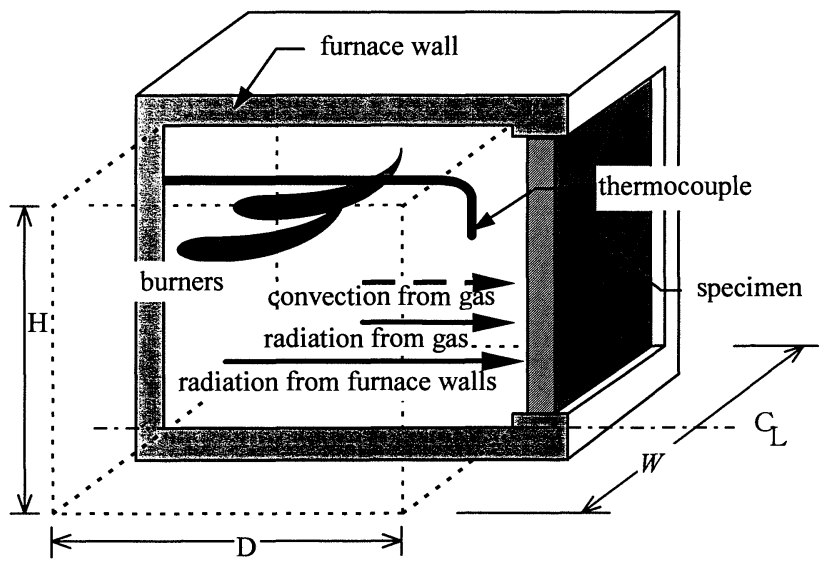

FIGURE 1 geometry of the fire resistance test furnace 


\section{Radiative Heat Transfer between Surfaces and Gas Volume}

The inter reflection of radiation between surfaces and gas volume was taken into account. The furnace gas and surfaces were assumed to be gray and diffuse bodies. The furnace wall surfaces and specimen surface were divided into $n$ elements. The incoming radiative heat flux on surface element $i(i=1,2,3, \cdots, n)$ is the sum of the radiative heat flux from other surfaces (reflection and emission) and gas (emission). Neglecting the spatial distribution of gas temperature, we get the following simultaneous equations ${ }^{6}$,

$$
q_{i n c, i}=\sum_{\substack{j=1 \\ j \neq i}}^{n}\left(1-\varepsilon_{j}\right) F_{i-j} q_{i n c, j}+\sum_{\substack{j=1 \\(j \neq i)}}^{n} F_{i-j} \varepsilon_{j} \sigma T_{j}^{4}+F_{i-g} \sigma T_{g}^{4} \quad(i=1,2,3, \cdots, n),
$$

where $F_{i-j}$ and $F_{i-g}$ are the shape factors between surfaces and between surface and gas volume,

$$
\begin{aligned}
& F_{i-j} \equiv \frac{1}{A_{i}} \iint_{A_{i}} \iint_{A_{j}} e^{-k r\left(\theta_{i}, \phi\right)} \frac{\cos \theta_{i} \cos \theta_{j}}{\pi r^{2}} d A_{j} d A_{i}, \\
& F_{i-g} \equiv \frac{1}{A_{i}} \iint_{A_{i}} \iint_{\mathcal{L}_{j}}\left(1-e^{-k r\left(\theta_{i}, \phi\right)}\right) \frac{\cos \theta_{i} \cos \theta_{j}}{\pi r^{2}} d A_{j} d A_{i},
\end{aligned}
$$

and $k$ is the absorption coefficient of furnace gas. Using Modak's method ${ }^{7)}$, the absorption coefficient was calculated as a function of temperature and composition of furnace gas,

$$
k=k\left(T_{g}, P_{\mathrm{CO}_{2}}, P_{\mathrm{H}_{2} \mathrm{O}}, C_{\text {soot }}\right) \text {. }
$$

The partial pressures of carbon dioxide and water vapor, $P_{\mathrm{CO}_{2}}, P_{\mathrm{H}_{2} \mathrm{O}}$, were calculated by stoichiometric relations assuming the perfect combustion of fuel. The soot concentration $C_{\text {soot }}$ was evaluated by Kunitomo's empirical formula for industrial furnaces ${ }^{8)}$.

After solving the simultaneous equations (1) for $q_{i n c}$, net radiative heat flux absorbed by the surface can be calculated by,

$q_{n e t, i}=\varepsilon_{i} q_{i n c, i}-\varepsilon_{i} \sigma T_{i}^{4} \quad(i=1,2,3, \cdots, n)$.

\section{Convective Heat Flux}

The convective heat flux absorbed by the surface $i$, is

$$
q_{c n v, i}=h_{i}\left(T_{g}-T_{i}\right) \text {. }
$$

The convective heat transfer coefficient $h_{i}$ was calculated by an empirical formula developed by Martin $^{9)}$ for jet flow impinging on a flat surface. A typical jet velocity during fire resistance test is $6 \mathrm{~m} / \mathrm{s}$, which results in the heat transfer coefficient of $50\left[\mathrm{~W} / \mathrm{m}^{2} . \mathrm{K}\right]$ at specimen surface. 


\section{Wall Heat Conduction}

To calculate the surface temperature of wall surfaces, $T_{i}\left(=T_{w, i}(0, t)\right)$, one dimensional wall heat conduction equation,

$$
\rho_{i} c_{i} \frac{\partial T_{w, i}\left(x_{i}, t\right)}{\partial t}=\lambda_{i} \frac{\partial^{2} T_{w, i}\left(x_{i}, t\right)}{\partial x_{i}^{2}}, \quad(i=1,2,3, \cdots, n),
$$

was solved for each element, where $x_{i}$ denotes the distance from surface $i$ into wall. The boundary condition is coupled with radiative and convective heat flux, namely,

$q_{n e t, i}+q_{c n v, i}=-\left.\lambda \frac{\partial T_{w, i}\left(x_{i}, t\right)}{\partial x_{i}}\right|_{x_{i}=0}, \quad(i=1,2,3, \cdots, n)$.

\section{Heat Balance of Thermocouples}

In general, gas temperature and the thermocouple temperature are not identical. Thermocouple temperature is calculated so that the heat balance of the thermocouple is satisfied. Considering the radiative and convective heat exchange, the heat balance is

$V_{t c} \rho_{t c} c_{t c} \frac{\partial T_{t c}}{\partial t}=A_{t c} \varepsilon_{t c} q_{i n c, t c}-A_{t c} \varepsilon_{t c} \sigma T_{t c}^{4}+A_{t c} h_{t c}\left(T_{g}-T_{t c}\right)$

The L.H.S denotes the heat stored in thermocouple element per unit time. The incoming radiative heat flux was calculated by

$q_{i n c, t c}=\sum_{j=1}^{n} F_{t c-j}\left\{\left(1-\varepsilon_{j}\right) q_{i n c, j}+\varepsilon_{j} \sigma T_{j}^{4}\right\}+F_{t c-g} \sigma T_{g}^{4}$,

where $F_{t c-i}$ and $F_{t c-g}$ are the shape factors between thermocouple and surfaces and between thermocouple and gas volume, respectively. In case of bare and sheathed thermocouples (Figure $2 \mathrm{a}, 2 \mathrm{~b}$ ), the shape factors were calculated for all the directions and averaged. In case of plate thermocouple (Figure 2c), the shape factors were calculated only in the direction to view the furnace (not to view the specimen), because the specimen's side of the thermocouple is insulated.

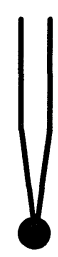

a) bare

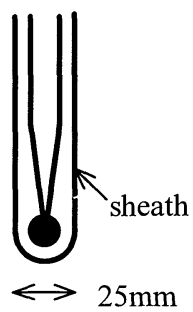

b) sheathed

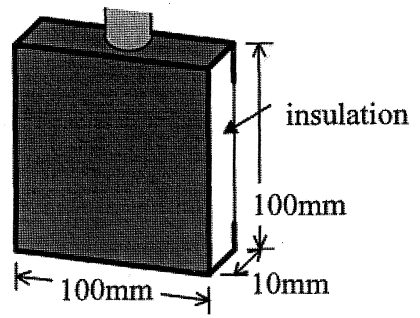

c) plate

FIGURE 2 geometry of thermocouples 
The convective heat transfer coefficient was calculated by an empirical formula for a rod in a gas stream ${ }^{10}$, assuming that the gas velocity around the thermocouple is $2 \mathrm{~m} / \mathrm{s}$. Typical values are $60\left[\mathrm{~W} / \mathrm{m}^{2} . \mathrm{K}\right]$ for bare thermocouples, $30\left[\mathrm{~W} / \mathrm{m}^{2} . \mathrm{K}\right]$ for sheathed thermocouples, $20\left[\mathrm{~W} / \mathrm{m}^{2} . \mathrm{K}\right]$ for plate thermocouples.

\section{Solution Algorithm}

All the equations were coupled together and solved by iterative procedure. At each simulation time, gas temperature was used to calculate the radiative and convective heat flux, wall temperatures and thermocouple temperature. Until the thermocouple temperature agreed with the standard temperature, the gas temperature was corrected. The whole process was repeated until the end of simulation time.

\section{VERIFICATION OF THE MODEL}

To verify the model, a fire resistance test carried out by Matsuyama et $a l^{11)}$ was simulated.

\section{Experimental Conditions}

A $5 \mathrm{~mm}$ thick steel plate specimen in Figure 3 was heated by a vertical furnace. Lower half of the steel plate is accompanied with $25 \mathrm{~mm}$ thick ceramic fiber and $100 \mathrm{~mm}$ thick ALC wall. Two Gardon foil type water cooled heat flux gauges were attached to measure the incoming (radiative plus convective) heat flux.

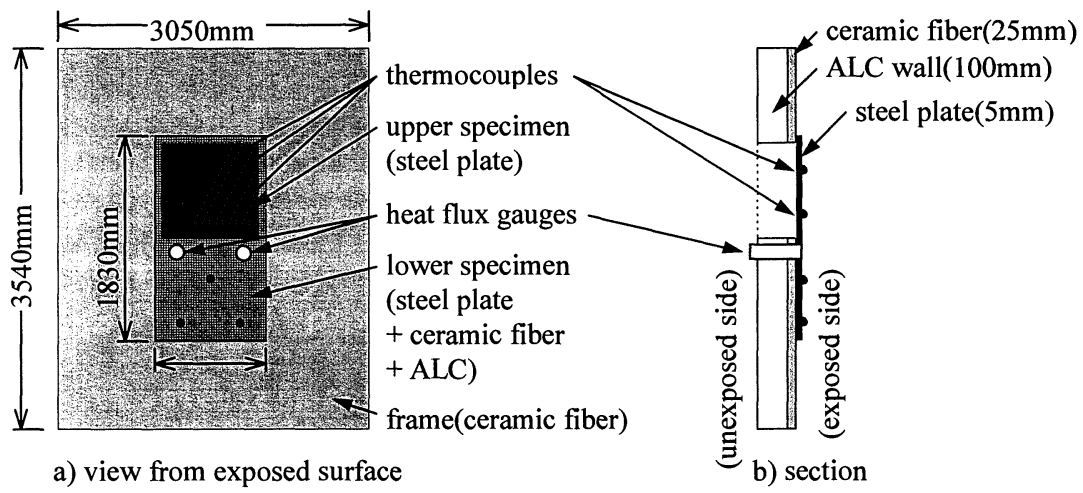

FIGURE 3 schematics of the specimen

TABLE 1 thermal properties of furnace materials ${ }^{10)}$

\begin{tabular}{lccc}
\hline material & $\begin{array}{c}\text { emisivity } \\
{[-]}\end{array}$ & $\begin{array}{c}\text { thermal conductivity } \\
{[\mathrm{W} / \mathrm{m} \cdot \mathrm{K}]}\end{array}$ & $\begin{array}{c}\text { thermal inertia } \\
{\left[\mathrm{J} / \mathrm{m}^{2} \cdot \mathrm{s}^{1 / 2} \cdot \mathrm{K}\right]}\end{array}$ \\
\hline steel & 0.8 & 80.3 & 16713 \\
ceramic fiber & 0.7 & 0.04 & 86 \\
ALC & 0.94 & 0.15 & 313 \\
thermocouple sheath & 0.8 & 51.6 & 13851 \\
\hline
\end{tabular}


The specimen was heated in accordance with Japanese fire resistance test procedure ${ }^{12)}$. The standard time- temperature curve is almost the same as that defined in ISO $834^{13)}$. The furnace was controlled by sheathed thermocouples of $25 \mathrm{~mm}$ diameter that located $30 \mathrm{~mm}$ apart from specimen surface. The furnace size was $W=3.23, H=3.56, D=0.955[\mathrm{~m}]$. The furnace wall was lined with ceramic fiber. The furnace was oil (kerosene) fired. The excess air ratio was about 1.5 . In this burning condition, soot concentration was almost negligible ${ }^{8}$. The partial pressures of carbon dioxide and water vapor were 0.09 and 0.096 [ata], respectively. The absorption coefficient of furnace gas could be about $0.25\left[\mathrm{~m}^{-1}\right]$. The thermal properties of furnace materials are listed in Table 1.

\section{Calculation Results and Comparison with Experimental Data}

The calculation results are shown with experimental data in figures 4 and 5 . Figure 4 shows the heat flux absorbed by a heat flux gauge. To compare with experiment, the same quantity

$$
q_{\text {gauge }}=q_{\text {inc(sample })}+h_{\text {sample }}\left(T_{g}-T_{\text {gauge }}\right) \text {, }
$$

was plotted, where $T_{\text {gauge }}$ is the surface temperature of heat flux gauge (water cooled, $300 \mathrm{~K}$ assumed). The results are in good agreement except in the first ten minutes. The discrepancies in this period is mainly due to the uncertainties in convective heat transfer coefficient and due to the spatial distribution of gas temperature.

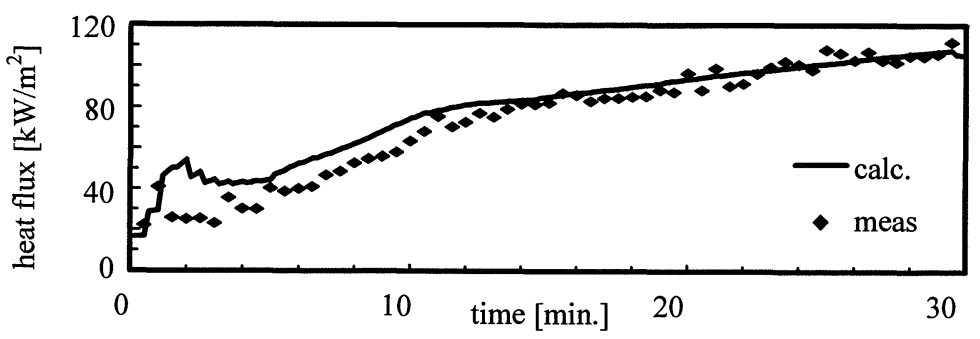

FIGURE 4 heat flux absorbed by water cooled heat flux gauge

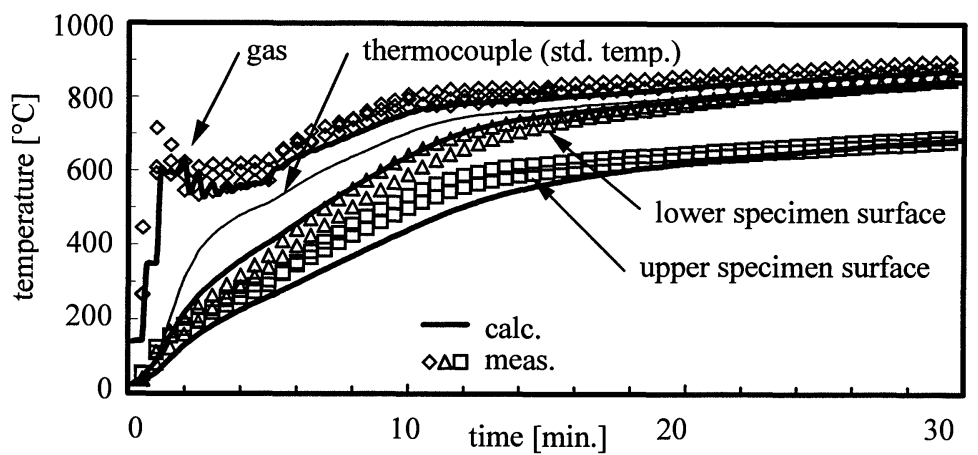

FIGURE 5 gas, thermocouple and specimen surface temperature 


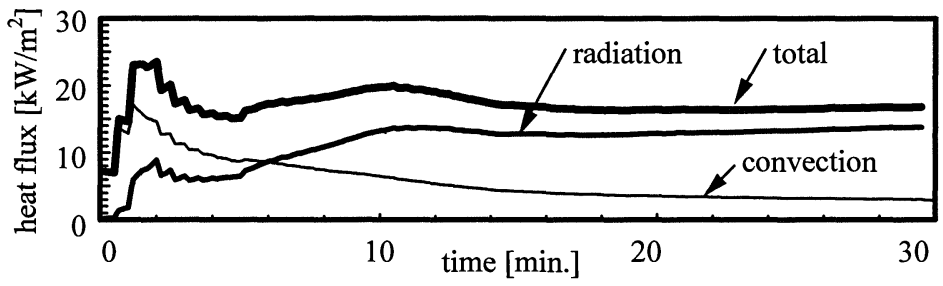

FIGURE 6 heat flux absorbed by upper specimen surface ( $5 \mathrm{~mm}$ steel)

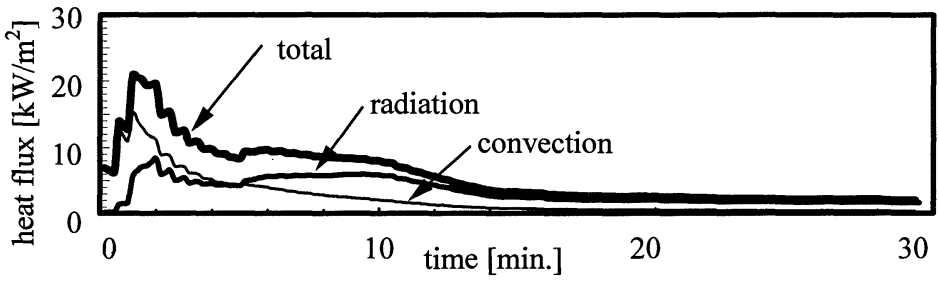

FIGURE 7 heat flux absorbed by lower specimen surface $(5 \mathrm{~mm}$ steel $+25 \mathrm{~mm}$ ceramic fiber $+100 \mathrm{~mm}$ ALC)

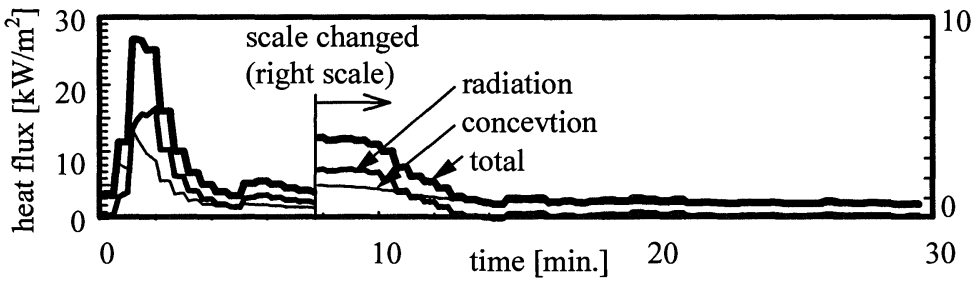

FIGURE 8 heat flux absorbed by thermocouple sheath (25mm- dia. circular steel tube)

In Figure 5, the gas temperature and specimen's surface temperature are compared. Good agreements were obtained in gas temperature and lower specimen's temperature. It should be noted that the gas temperature is not the same as thermocouple temperature, but considerably higher than the thermocouple temperature. Because of the heat capacity of the thermocouple sheath, the gas temperature must be much higher than the standard temperature especially in the early stage. Even after 15 minutes, the gas temperature is slightly higher than the thermocouple temperature. As will be described in the next section (Figure 8), the thermocouple gains heat mainly by convection from gas. Thus the gas temperature is slightly higher than the thermocouple temperature throughout the test.

\section{Heat Transfer Mechanism}

Using the calculation results in previous section, the histories of heat flux on specimen surfaces are plotted in figures 6 and 7. Both in cases of upper and lower specimens, convective heat flux is dominant in the early stage. However the radiative heat flux is dominant after 10 minutes. The radiative fraction is about $70 \%$ of the total heat gain of the specimen. In contrast, the thermocouple is sensitive to convective heat transfer as shown in Figure 8 . Radiative fraction is only $20 \%$. The difference in radiative fraction between the 
thermocouple and specimen surface is one of the reason of scatter of the test results.

\section{QUANTITATIVE ANALYSIS ON THE EFFECT OF FURNACE CONSTRUCTIONS AND THERMOCOUPLE GEOMETRY}

To investigate the importance of furnace size, wall lining materials, fuel and thermocouple geometry, a number of calculations were carried out. A $5 \mathrm{~mm}$ thick steel plate was selected as the specimen in the following calculations. The size of specimen is the same as that in previous section $(1.83 \times 0.915 \mathrm{~m})$. Calculations were carried out for all the combinations of the parameters listed in Table 2.

\section{TABLE 2 calculation conditions}

\begin{tabular}{ll}
\hline parameters & \\
furnace depth* & $0.17,0.5,0.95,3.0 \mathrm{~m}$ \\
fuel & electricity $(k=0)$, kerosene $(0.24)$, heavy oil $(0.5)$, black furnace $(\infty)$ \\
wall lining material & ceramic fiber, fire brick \\
thermocouple & bare, sheathed $(25 \mathrm{~mm}$ dia. steel tube), plate $(100 \times 100 \times 10 \mathrm{~mm})$ \\
\hline
\end{tabular}

* Furnace width and height are not changed. $(W=3.23, H=3.56)$

\section{Calculation Results}

The calculated results are summarized in figures 9 to 14, categorized by wall lining material and thermocouple geometry. The left graph a) in each figure shows the exposed surface temperature of the specimen at 30 minutes. The center b) and right c) graphs are the radiative and convective heat gain of the specimen during 30 minutes, respectively.

In Figure 9, the results are shown for ceramic fiber furnaces with bare thermocouple control. The surface temperature scatters in the range of 655 and $675^{\circ} \mathrm{C}$ depending on the furnace depth and absorption coefficient of furnace gas. As shown in graph $9 \mathrm{~b}$ ), the radiative heat gain increases as the furnace depth and absorption coefficient increases. Conversely, as shown in graph 9c), the convective heat gain decreases. These two effects compensate each other to result in fairly small variation of specimen temperature, except in the extreams of $k D \rightarrow 0$. Also in the case of fire brick wall furnaces (Figure 10), similar tendency was found. However the range of scatter is much larger than the ceramic fiber wall furnaces. In the extreme case that $k D \rightarrow 0$, the radiative heat gain tends to zero or negative value.

In case of sheathed thermocouple control (figures 11 and 12), the specimen temperature slightly increases as $k D \rightarrow 0$. As the thermocouple is less sensitive to convection, gas temperature must be much higher than the standard temperature. As a result, convective heat flux to specimen is increased to compensate the decrease of radiative heat flux. The scatter in specimen surface temperature is smaller than bare thermocouple control.

The use of plate thermocouple is aimed to reduce the scatter of the test results between furnaces. As shown in Figure 13, there is no significant difference in specimen surface temperature in case of ceramic fiber wall furnaces. Also in case of brick wall furnaces, as shown in Figure 14, the scatter is small if the non dimensional furnace depth $k D$ is 
sufficiently large. However, in the range of small $k D$, the scatter of specimen temperature is intensified. As shown in Figure 14c), convective heat gain is greatly increased, which increases the specimen temperature considerably.
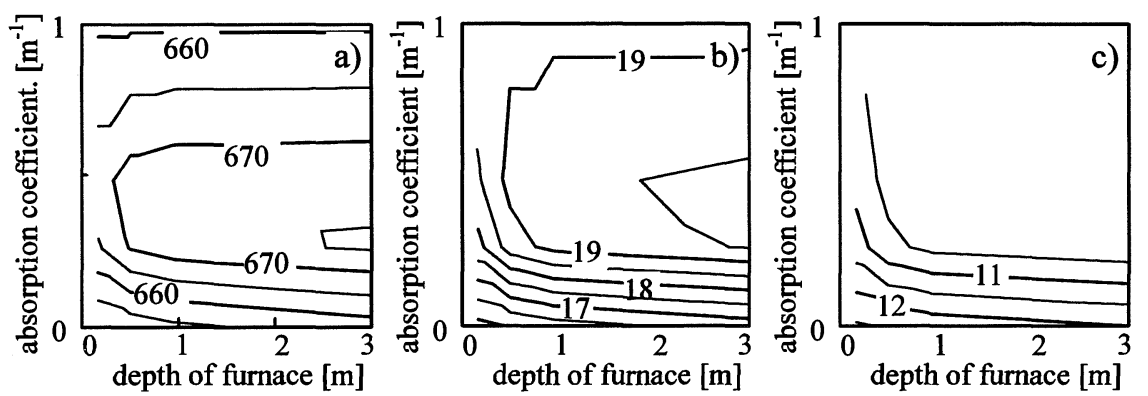

FIGURE 9 calculation results for the cases of ceramic fiber wall furnaces with bare thermocouple control: a) specimen surface temperature at 30 minutes $\left[{ }^{\circ} \mathrm{C}\right]$, b) radiative heat gain of the specimen during 30 minutes $\left[\mathrm{MJ} / \mathrm{m}^{2}\right]$, c) convective heat gain of specimen during 30 minutes $\left[\mathrm{MJ} / \mathrm{m}^{2}\right]$
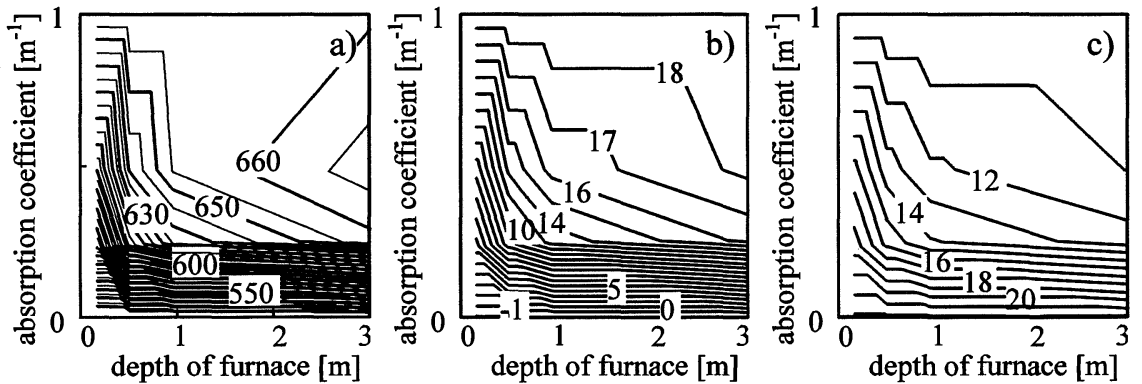

FIGURE 10 calculation results for the cases of fire brick wall furnaces with bare thermocouple control (see the caption of Figure 9 for explanation)
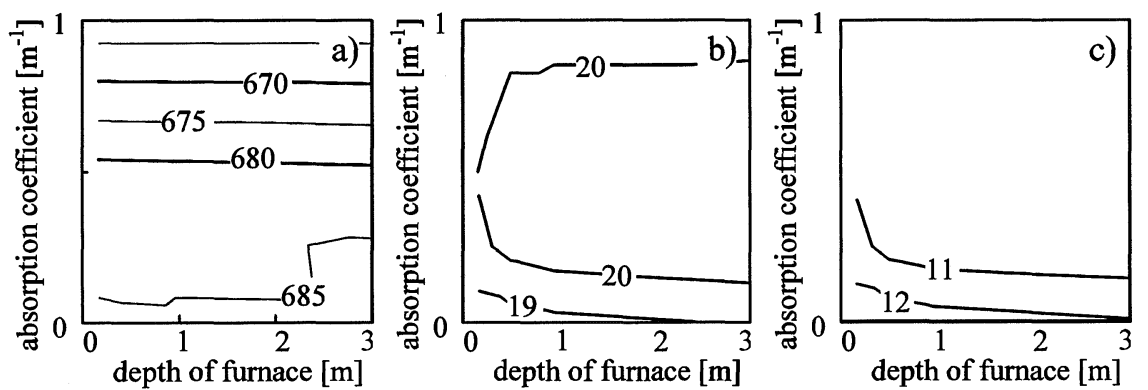

FIGURE 11 calculation results for the cases of ceramic fiber wall furnaces with sheathed thermocouple control (see the caption of Figure 9 for explanation) 

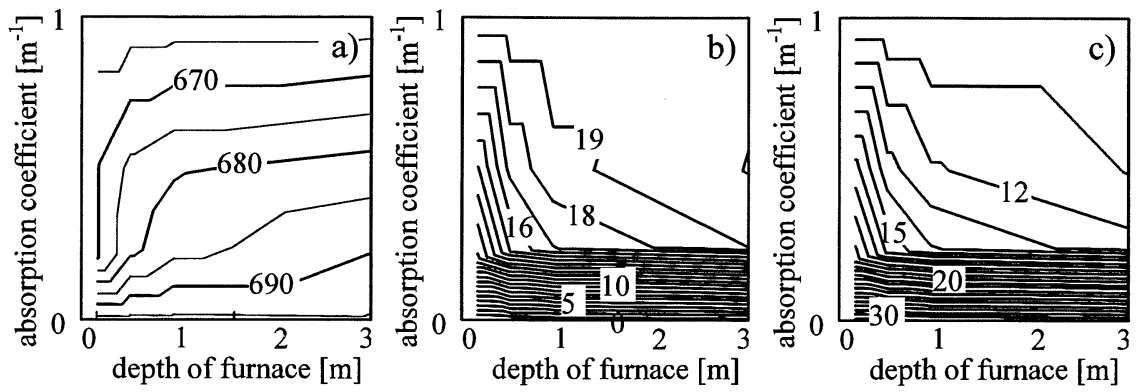

FIGURE 12 calculation results for the cases of fire brick wall furnaces with sheathed thermocouple control (see the caption of Figure 9 for explanation)
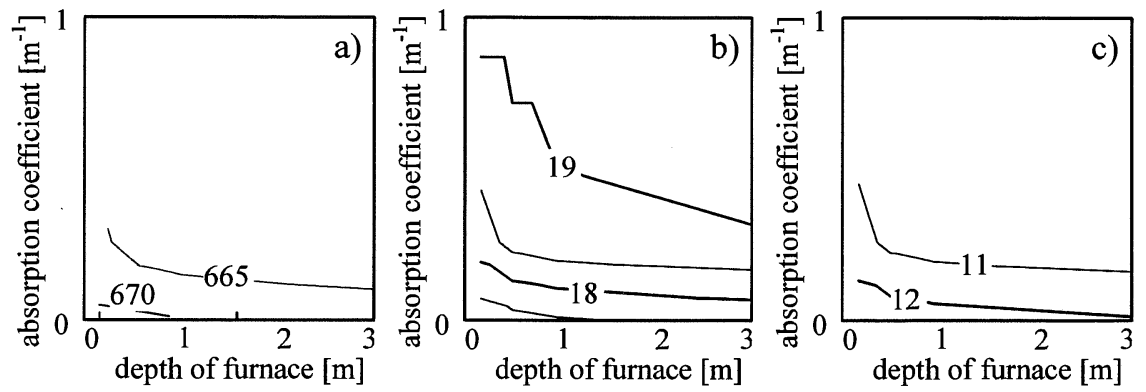

FIGURE 13 calculation results for the cases of ceramic fiber wall furnaces with plate thermocouple control (see the caption of Figure 9 for explanation)
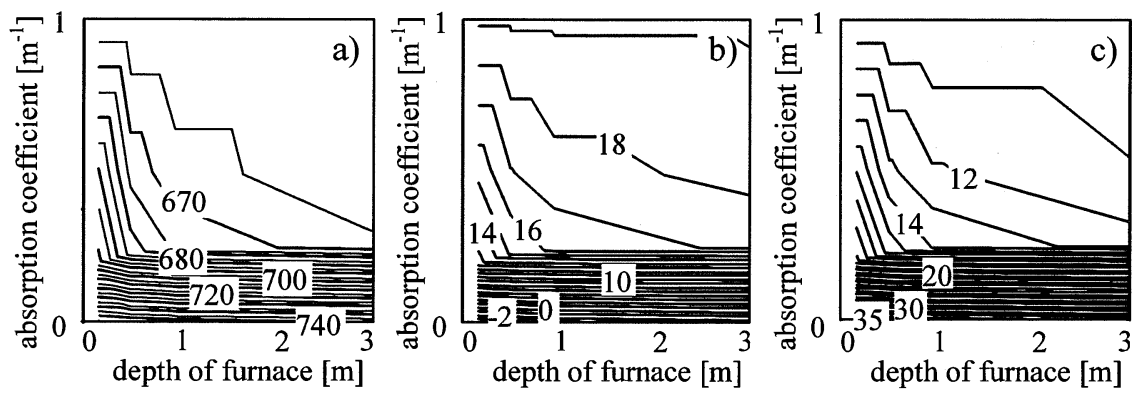

FIGURE 14 calculation results for the cases of fire brick wall furnaces with plate thermocouple control (see the caption of Figure 9 for explanation)

\section{DISCUSSION}

In Figure 15, the calculated surface temperature of specimen at 30 minutes are plotted as a function of non dimensional furnace depth, $k D$. In case of ceramic fiber wall furnaces (open symbols), the scatter is fairly small whatever the thermocouple is used for furnace control. 
In case of brick wall furnaces (filled symbols), the scatter is inevitable if $k D$ is small. As $k D \rightarrow 0$, specimen temperature is reduced in case of bare thermocouple control, increased in case of plate thermocouple control. The difference in the tendency is due to the difference in the sensitivity of thermocouple to radiative heat transfer. Sheathed thermocouple control has the intermediate feature of the two. The scatter happen to be small. Considering that the present results are valid only for a steel plate specimen, it is still open to question whether the sheathed thermocouple works always the best of the three.

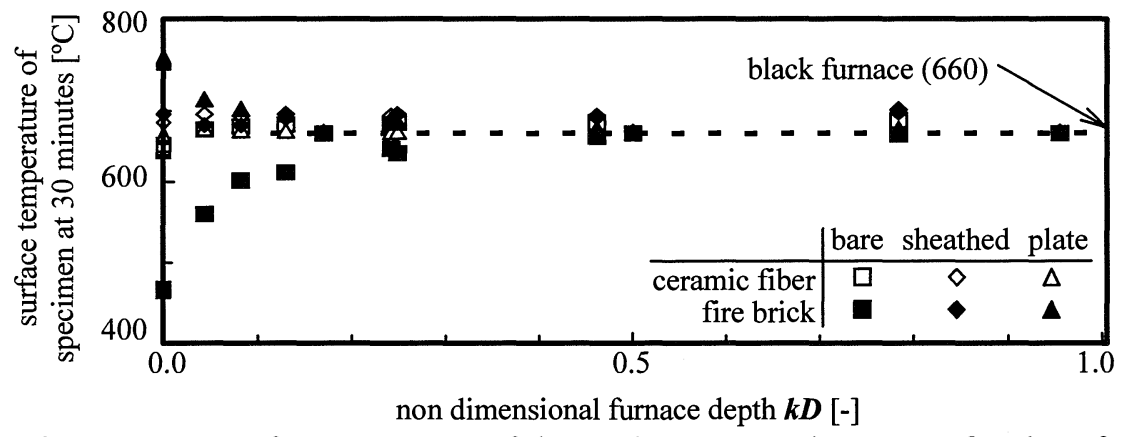

FIGURE 15 surface temperature of the specimen at 30 minutes as a function of non dimensional furnace depth $k D[-]$

\section{CONCLUSIONS}

A heat transfer model was developed to investigate the reasons of scatter of fire resistance test results. The analysis clarified that 1 ) the wall lining material is the dominant factor that influences the heat impact on specimen, and that 2) the plate thermocouple marginally reduce the scatter of results. Thus, in order to get the same test results using different furnaces, the thermal inertia of wall lining material should be small (e.g. ceramic fiber), or the non dimensional furnace depth, $k D$, should be large enough.

\section{ACKNOWLEDGEMENTS}

The authors would like to thank Dr. Tanaka, Mr. Motegi, Mr. Masuyama and Prof. Wakamatsu for valuable information and suggestions on their test results.

\section{NOMENCLATURE}

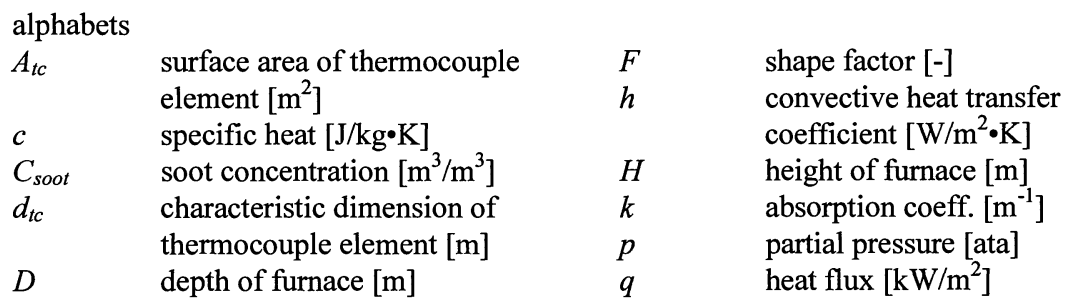




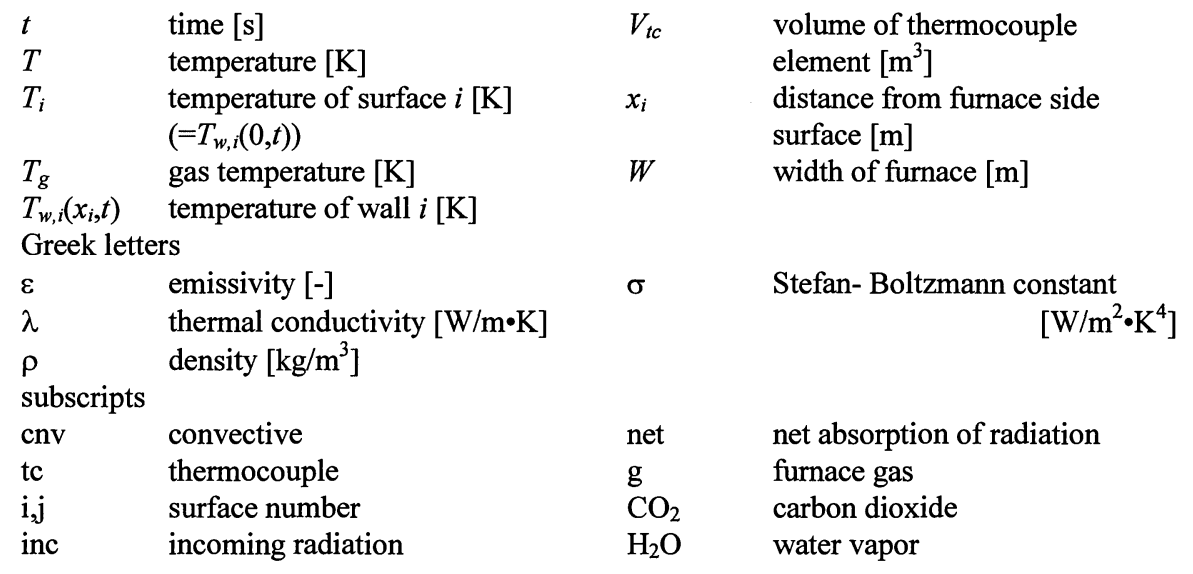

\section{REFERENCES}

1. Wickström, U., “A Proposal Regarding Temperature Measurements in Fire Test Furnaces", Swedish National Testing Institute, SP-RAPP 1986:17, 1986

2. Cooke, G., M., E., Use of Plate Thermometers for Standardising Fire Resistance Furnaces, BRE Occasional Paper, Building Research Establishment, U.K., 1994

3. Wakamatsu, T., "On the Heat Transmissions Relating to the Fire Endurance Test", Bulletin of the Fire Prevention Society of Japan, 17(1), pp.43-55, 1967

4. Harmathy, T., Z., "The Fire resistance Test and its Relation to Real- World Fires", Fire and Materials, 5(3), pp. 112- 122, 1981

5. Yabuki, Y., Harada, K., Terai, T., "Heat Transfer in Fire Resistance Test Furnaces with Particular Reference to Gas Radiation", Proceedings of the 2nd Asia- Oceanian Conference on Fire Science and Technology, pp. 262- 273, 1995

6. Hottel, H., C., Sarofim, A., F., Radiative Transfer, McGraw-Hill, New York, 1967

7. Modak, A., T., "Radiation from Products of Combustion", Fire Research, 1, pp.339$361,1978 / 79$

8. Kunitomo, T., "Mean Radiation from Luminous Flame of Jet Combustion of Liquid Fuels", Transactions of Japan Society of Mechanical Engineers., Series. 2, 37(304), pp. 2327-2335, 1971

9. H. Martin, "Heat and Mass Transfer between Impinging Gas Jets and Solid Surfaces", Advances in Heat Transfer, 13, pp. 1- 60, 1977

10. Japan Society of Mechanical Engineers, JSME Handbook on Heat Transfer, 1993

11. Matsuyama, K., Motegi, T., Tanaka, T., Wakamatsu, T., Proceedings of the Annual Meeting of Japan Society of Fire Science and Engineering, pp. 294- 297, 1996

12. Notification No. 2999, Ministry of Construction, Japan Government, 1961

13. ISO/TC92/SC2, ISO834 Fire- Resistance Tests - Elements of Building Construction 